\title{
Analisis Biaya Medis Langsung Pasien Hemodialisa di Rumah Sakit X Wilayah Bekasi
}

\section{Analysis of Direct Medical Costs of Hemodialysis Patients in Hospital X Bekasi}

\author{
lin Ruliana Rohenti ${ }^{*}$, Hesty Utami Rahmadaniati, Prih Sarnianto \\ Fakultas Farmasi, Universitas Pancasila, \\ Jl. Srengseng Sawah, Jagakarsa, Jakarta Selatan 12640, Indonesia \\ *Corresponding author email: iinrulianarohenti@gmail.com
}

Received 17-10-2019 Accepted 12-12-2019 Available online 30-12-2019

\begin{abstract}
ABSTRAK
Pasien Penyakit Ginjal Kronik (PGK) tahap akhir diindikasikan untuk memperoleh terapi renal replacement therapy, yaitu dialisis. Dialisis yang dimaksud baik dialisis peritonial maupun hemodialisis. Pembiayaan PGK merupakan peringkat kedua pembiayaan terbesar dari BPJS kesehatan setelah penyakit jantung. Tujuan penelitian ini adalah menganalisis pengobatan dan biaya rata-rata menurut perspektif rumah sakit dibandingkan dengan tarif INA CBGs pada pasien PGK yang menjalani hemodialisa rawat jalan di RS X. Jenis penelitian ini adalah penelitian observasional dengan pendekatan cross sectional (retrospektif) menggunakan dokumen rekam medis, data keuangan, dan data pengobatan pasien. Analisis biaya membandingkan biaya riil dengan biaya ideal menggunakan uji Wilcoxon. Data penelitian adalah data kuantitatif. Sampel penelitian ini berjumlah 74 pasien. Hasil penelitian ini menunjukkan biaya riil untuk satu kali kunjungan hemodialisa di RS $X$ adalah sebesar Rp705.523,00. Besaran tarif INA CBGs untuk hemodialisa rumah sakit pemerintah kelas $B$ adalah Rp879.100,00. Biaya ideal untuk manajemen terapi anemia sebesar Rp1.056.946,00. Analisis biaya riil dengan ideal menyatakan perbedaan bermakna dengan nilai $p<0,05(p=0,018)$. Biaya riil lebih rendah dari pada tarif INA CBGs. Biaya ideal lebih tinggi daripada tarif INA CBGs.
\end{abstract}

Kata kunci: analisis biaya, hemodialisa, penyakit ginjal kronik.

\begin{abstract}
Patients with Chronic Kidney Disease (CKD) in the final stages are indicated to obtain renal replacement therapy, namely dialysis. Dialysis is meant both peritonial dialysis and hemodialysis. CKD financing is the second largest financing from BPJS after heart disease. The purpose of this study was to analyze average cost according to the hospital perspective compared with INA CBGs rates in CKD patients undergoing outpatient hemodialysis at RS $X$. This type of research was an observational study with cross
\end{abstract}


sectional (retrospective) approach using medical record documents and financial data. Cost analysis compared real costs with ideal costs using the Wilcoxon test. Treatment analysis used descriptive statistics. Research data was quantitative data. The sample of this study was 74 patients. The results of this study indicated the real cost for a one-time hemodialysis visit at Hospital $X$ was IDR 705,523,00. The amount of INA CBG rates for hemodialysis at Class B Government Hospitals was IDR 879,100. The ideal cost for management of anemia therapy was IDR 1,056,946. Analysis of real costs ideally stated a significant difference with a value of $p<0.05(p=0.018)$. Real costs were lower than INA CBGs tariffs. Ideal costs were higher than INA CBGs rates.

Key words: chronic kidney disease, cost analysis hemodialysis.

\section{Pendahuluan}

Pada era Jaminan Kesehatan Nasional (JKN), pembiayaan kesehatan pada Fasilitas Kesehatan Rujukan Tingkat Lanjutan (FKRTL) menggunakan tarif Indonesian Case Based Group (INACBGs), tetapi seringkali biaya riil lebih besar dari tarif INA-CBGs (Azalea et al., 2016). Pada penelitian terdahulu menyatakan bahwa menurut perspektif pasien, biaya langsung medis hemodialisis (HD) selama sebulan di RS B Rp5.215.331,00 dan di RS C Rp7.781.744,00. Besaran tarif CBGs untuk RS kelas B adalah Rp962.800,00 dan kelas C adalah Rp893.300,00 (Firda dan Thabrany, 2016).

Pasien Penyakit Ginjal Kronik (PGK) tahap akhir diindikasikan untuk memperoleh terapi renal replacement therapy, yaitu dialisis. Dialisis yang dimaksud baik dialisis peritonial maupun hemodialisis (Supadmi, 2011). Pembiayaan PGK merupakan peringkat kedua pembiayaan terbesar dari BPJS kesehatan setelah penyakit jantung (Kemenkes RI, 2017). Dengan diberlakukannya INA-CBGs pada pembiayaan rumah sakit bagi pasien, maka analisis biaya pengobatan rawat jalan bagi penderita PGK sangat dibutuhkan dalam perencanaan pengobatan sehingga rumah sakit dapat melakukan penghematan biaya agar rumah sakit tidak merugi. Analisis biaya tersebut selain berguna dalam hal mengajukan klaim kepada pihak asuransi kesehatan juga dapat digunakan dalam memberikan pengobatan yang tepat bagi pasien berdasarkan data biaya pengobatan.

Evaluasi ekonomi kesehatan dapat membantu meringankan beban sumber daya yang langka dengan meningkatkan efisiensi alokasi pembiayaan kesehatan. Pada penelitian sebelumnya menyatakan bahwa rerata total biaya hemodialisa pasien Askes pada pelayanan rawat jalan per orang per tahun mencapai Rp62.543.379,08. Rerata biaya hemodialisa yang ditanggung oleh PT Askes mencapai Rp56.501.237,90. Rerata biaya yang ditanggung oleh pasien mencapai Rp6.042.141,18 per orang per tahun. (Wiguna et al., 2013).

Tujuan dari penelitian ini adalah untuk mengetahui besar rata-rata biaya 
medis langsung di Rumah Sakit $X$ Wilayah Bekasi.

\section{Metode Penelitian}

Sampel dalam penelitian ini adalah pasien yang terdiagnosa penyakit ginjal kronik yang menjalani hemodialisa di Rumah Sakit X Wilayah Bekasi tahun 2017. Sampel yang memenuhi penelitian sejumlah 74 pasien.

Kriteria inklusi meliputi pasien minimal usia 18 tahun, pasien hemodialisa rawat jalan, pasien merupakan peserta BPJS kesehatan, memiliki kelengkapan data rekam medik, data pengobatan dan data biaya/tagihan pasien yang lengkap. Sedangkan kriteria eksklusi meliputi pasien yang tidak memiliki kelengkapan data rekam medik, data pengobatan atau data biaya/tagihan pasien yang lengkap dan pasien dengan penyakit berat seperti tumor dan kanker.

Penelitian ini menggunakan deskriptif kuantitatif. Analisis biaya dilakukan dengan membandingkan biaya riil dengan biaya ideal menggunakan uji Wilcoxon.

Cara pengambilan data menggunakan metode retrospektif yang berasal dari catatan rekam medik, data pengobatan, dan data keuangan pasien gagal ginjal kronik yang menjalani hemodialisa rawat jalan di RS X periode 1 Januari sampai 31 Desember 2017. Data yang dikumpulkan dari rekam medik yaitu nomor rekam medik, umur pasien, jenis kelamin, diagnosa, data pemeriksaan laboratorium, obat yang digunakan. Data keuangan meliputi biaya obat dan alat kesehatan, biaya hemodialisa, biaya penunjang diagnostik dan biaya konsultasi dokter.

\section{Analisa Data}

Perhitungan biaya medis langsung rata-rata meliputi biaya obat dan alat kesehatan yang dihitung dengan menjumlahkan biaya obat dan alat kesehatan yang diterima pasien, biaya penunjang diagnostik yang dihitung dengan menjumlahkan biaya yang digunakan untuk pemeriksaan laboratorium, biaya hemodialisa yang dihitung dengan menjumlahkan biaya hemodialisa, dan biaya medis langsung yang dihitung dengan menjumlahkan semua biaya obat, alat kesehatan/bahan habis pakai, pemeriksaan laboratorium, hemodialisa set, dan biaya konsultasi dokter pada pasien penyakit ginjal kronik yang menjalani hemodialisa.

\section{Hasil dan Pembahasan}

Karakteristik Sosiodemografi

Pada penelitian ini karakteristik pasien berdasarkan rentang usia (Tabel 1) menunjukkan bahwa penyakit ginjal kronik yang menjalani hemodialisa paling banyak pada usia 46-55 tahun sejumlah 26 pasien $(35,14 \%)$ dan usia $56-65$ tahun sejumlah 23 pasien $(31,08 \%)$. Hal ini sesuai dengan data IRR tahun 2015 yang menunjukkan bahwa usia pasien penyakit ginjal kronik paling banyak pada rentang usia $45-54$ tahun $(29,46 \%)$ dan 55-64 tahun $(27,31 \%)$.

Karakteristik berdasarkan jenis kelamin menunjukkan jumlah pasien laki-laki yang menderita penyakit ginjal kronik yang menjalani hemodialisa lebih 
banyak yaitu 44 pasien (59,46\%) laki-laki (56,82\%) lebih banyak dibandingkan jumlah pasien perempuan. dibandingkan perempuan $(43,18 \%)$. Jenis Hal ini sesuai dengan IRR Tahun 2015, penyakit penyerta yang dialami pasien dimana insidensi jenis kelamin penyakit ginjal kronik yang menjalani terbanyak pada kasus penyakit ginjal hemodialisa di RS X Wilayah Bekasi kronik adalah laki-laki (54,70\%). Pada adalah anemia sebanyak 72 pasien, penelitian yang dilakukan juga oleh Fitria hipertensi sebanyak 68 pasien, (2015) di Rumkital Dr. Mintoharjo pada kardiovascular sebanyak 24 pasien, dan tahun 2014, karakteristik sampel diabetes mellitus sebanyak 11 pasien.

berdasarkan jenis kelamin menunjukkan

Tabel 1. Karakteristik sosiodemografi pasien hemodialisa di Rumah Sakit $X$

\begin{tabular}{lcc}
\hline Karakteristik Sosiodemografis & Frekuensi (n=74) & Proporsi (\%) \\
\hline Usia & $22-70$ & - \\
Rentang & 53 & - \\
Median & 50,36 & - \\
Rerata (SD) & 4 & 5,41 \\
18-25 tahun & 6 & 8,11 \\
$26-35$ tahun & 11 & 14,86 \\
36-45 tahun & 26 & 35,14 \\
46-55 tahun & 23 & 31,08 \\
56-65 tahun & 4 & 5,41 \\
>65 tahun & & \\
Jenis Kelamin & 44 & 59,46 \\
Laki-laki & 30 & 40,54 \\
Perempuan & & \\
Tingkat Pendidikan & 1 & 1,35 \\
Tidak sekolah & 8 & 10,81 \\
SD & 14 & 18,92 \\
SMP & 44 & 59,46 \\
SMA & 7 & 9,46 \\
Perguruan tinggi & & \\
Status Pekerjaan & 51 & 68,92 \\
Bekerja & 23 & 31,08 \\
Tidak bekerja & & \\
Penyakit Penyerta/Komplikasi & 72 & 97,30 \\
Anemia & 68 & 91,89 \\
Hipertensi & 11 & 14,86 \\
Diabetes mellitus & 24 & 32,43 \\
Kardiovaskular & 2 & 2,70 \\
Tidak ada & &
\end{tabular}


Komponen Biaya Hemodialisa

Berdasarkan data pada Tabel 2, komponen biaya hemodialisa yang paling besar adalah biaya hemodialisa set sebesar Rp548.750,00, kemudian biaya konsultasi dokter sebesar Rp50.000,00. Penggunaan epotrex dan rinofer tidak dilakukan pada semua pasien namun berdasarkan hasil pemeriksaan laboratorium.

Komponen biaya tertinggi, yaitu pada hemodialisa set, diberikan satu kali pada setiap pasien. Biaya ini bisa diefisienkan dengan cara penggunaan re use. Kemudian penggunaan epo dan rinofer sebaiknya disesuaikan dengan kondisi pasien yang benar-benar membutuhkan terapi epo dan rinofer, sehingga biaya penggunaan epo dan rinofer dapat dikurangi.

Obat yang dipergunakan oleh pasien adalah obat rutin yang terdiri dari $\mathrm{NaCl}$, inviclot dan obat emergensi seperti deksametason yang digunakan saat tindakan HD. Obat rutin yang diberikan ke pasien untuk dibawa pulang digunakan tiga kali sehari yaitu asam folat, natrium bikarbonat dan kalsium karbonat, obat ini diberikan seminggu sekali kepada pasien. Semua obat tersebut sudah termasuk dalam biaya setiap melakukan HD. Obat-obat penyakit penyerta seperti amlodipin, insulin, furosemide, dan obat lainnya diberikan kepada pasien tanpa dikenakan biaya tambahan.

Tabel 2. Komponen biaya hemodialisa di Rumah Sakit $X$

\begin{tabular}{clcrcr}
\hline No & \multicolumn{1}{c}{ Komponen } & Satuan & Harga (Rp) & Qty & \multicolumn{1}{c}{ Harga (Rp) } \\
\hline 1 & Hemodialisa set & 1 kali & $548.750,00$ & 1 & $548.750,00$ \\
2 & Spuit 10 cc & Pcs & $1.570,00$ & 1 & $1.178,00$ \\
3 & Spuit 20 cc & Pcs & $3.720,00$ & 1 & $2.790,00$ \\
4 & Infuset & pcs & $4.775,00$ & 1 & $3.581,00$ \\
5 & BHP ruangan & 1 paket & $16.175,00$ & 1 & $12.131,00$ \\
6 & NaCl & pcs & $8.012,00$ & 3 & $18.027,00$ \\
7 & Inviclot & pcs & $54.994,00$ & 0,25 & $10.312,00$ \\
8 & Kidmin & pcs & $6.250,00$ & 1 & $4.688,00$ \\
9 & Obat emergency & 1 paket & $6.250,00$ & 1 & $4.688,00$ \\
& Total & & & & $619.025,00$ \\
10 & Epotrex & Pcs & $111.250,00$ & 1 & $83.438,00$ \\
11 & Rinofer & Pcs & $93.500,00$ & 1 & $70.125,00$ \\
& Total & & & & $823.775,00$ \\
12 & Konsultasi dokter & & $50.000,00$ & 1 & $50.000,00$ \\
13 & Laboratorium & & $35.688,00$ & 1 & $35.688,00$ \\
& & & & Total & $909.463,00$ \\
\hline
\end{tabular}


Tabel 3. Biaya dialiser pada pasien PGK yang menjalani hemodialisa di RS $X$

\begin{tabular}{lccr}
\hline Jenis Dialiser & Pemakaian & Biaya (Rp) & \multicolumn{1}{c}{ Total (Rp) } \\
\hline Dialiser baru & 1 & $548.750,00$ & $548.750,00$ \\
Dialiser re use & 5 & $392.000,00$ & $392.000,00$ \\
Jumlah & & & $2.508 .750,00$ \\
\multicolumn{2}{c}{ Biaya dialiser untuk satu kali tindakan hemodialisa } & $418.125,00$ \\
\hline
\end{tabular}

Berdasarkan data pada Tabel 3, biaya medis langsung yang diambil dari data tagihan RS terdiri dari 2 tarif yaitu dialiser non re use dan dialiser re use. Dialiser non re use digunakan pada saat pertama kali HD dengan tarif sebesar Rp548.750,00. Pada HD kedua sampai keenam menggunakan dialiser re use dengan tarif sebesar Rp392.000,00. Dalam penelitian ini digunakan rata-rata kedua tarif tersebut dengan memperhitungkan distribusi jumlah HD yang dilakukan. Biaya $\mathrm{HD}=$ $((1 \times R p 548.750,00)+(5 \times R p 392.000,00)) / 6$ $=\operatorname{Rp} 418.125,00$.

Tabel 4. Biaya penunjang diagnostik pada pasien PGK yang menjalani hemodialisa di RS $\mathrm{X}$

\begin{tabular}{lccr}
\hline \multicolumn{1}{c}{ Jenis Pemeriksaan } & Frekuensi/Tahun & Biaya (Rp) & \multicolumn{1}{c}{ Total (Rp) } \\
\hline Seri DHF (Hb, Ht, L, Trombo) & 12 & $45.000,00$ & $540.000,00$ \\
Ureum, creatinin & 12 & $50.000,00$ & $600.000,00$ \\
Elektrolit & 12 & $62.000,00$ & $744.000,00$ \\
GDS & 12 & $17.500,00$ & $210.000,00$ \\
Asam urat & 12 & $22.000,00$ & $264.000,00$ \\
Fe & 2 & $81.000,00$ & $162.000,00$ \\
Tibs & 2 & $81.000,00$ & $162.000,00$ \\
Jumlah & & $2.682 .000,00$ \\
Harga pemeriksaan laboratorium untuk satu kali tindakan hemodialisa & $27.938,00$ \\
\hline
\end{tabular}

Berdasarkan data pada Tabel 4, pemeriksaan laboratorium yang rutin meliputi pemeriksaan darah rutin, ureum creatinin, gula darah sewaktu, dan elektrolit, dilakukan sebulan sekali. Untuk pemeriksaan $\mathrm{Fe}$ dan TiBs dilakukan setiap 6 bulan sekali. Jadi biaya pemeriksaan laboratorium untuk pemeriksaan darah rutin, ureum creatinin, gula darah sewaktu, dan elektrolit dilakukan 12 kali dalam setahun, serta dua kali untuk pemeriksaan Fe dan TiBs dalam setahun. Jumlah biaya pemeriksaan laboratorium digabungkan dalam setahun dan didapatkan rata-rata biaya per bulan. Sehingga didapatkan rata-rata biaya pemeriksaan laboratorium $=$ 
((12xRp196.500,00)+(2xRp162.000,00)) / $12=$ Rp223.500,00/bulan. Biaya untuk alkes/bahan habis pakai (BHP) yang rutin dipakai setiap HD (spuit $10 \mathrm{cc}, 20 \mathrm{cc}$, infuset serta BHP ruangan) sebesar Rp26.240,00.

Tabel 5. Biaya alat kesehatan/bahan habis pakai pada pasien PGK yang menjalani hemodialisa di RS $X$

\begin{tabular}{lccc}
\hline Jenis & Jumlah & Biaya (Rp) & Total (Rp) \\
\hline Spuit 10 cc & 1 & $1.570,00$ & $1.570,00$ \\
Spuit 20 cc & 1 & $3.720,00$ & $3.720,00$ \\
Infuset & 1 & $4.775,00$ & $4.775,00$ \\
BHP ruangan & 1 & $16.175,00$ & $16.175,00$ \\
\multicolumn{2}{c}{ Biaya alkes/BHP untuk satu kali tindakan hemodialisa } & $26.240,00$ \\
\end{tabular}

Tabel 6. Biaya konsultasi dokter pada pasien PGK yang menjalani hemodialisa di RS X

\begin{tabular}{lccc}
\hline Jenis & Jumlah & Harga (Rp) & Total (Rp) \\
\hline Jasa konsultasi dokter & 1 & $50.000,00$ & $50.000,00$ \\
& & $50.000,00$ \\
\multicolumn{2}{c}{ Harga alkes/BHP untuk satu kali tindakan hemodialisa } & $50.000,00$ \\
\hline
\end{tabular}

Tabel 7. Biaya obat pada pasien PGK yang menjalani hemodialisa di RS $X$

\begin{tabular}{|c|c|c|c|}
\hline Nama Obat & Jumlah & Harga (Rp) & Total (Rp) \\
\hline \multicolumn{4}{|c|}{ Obat rutin/satu kali HD } \\
\hline $\mathrm{NaCl}$ & 3 & $8.012,00$ & $24.036,00$ \\
\hline Inviclot & 0,25 & $54.994,00$ & $13.749,00$ \\
\hline Kidmin & 1 & $6.250,00$ & $6.250,00$ \\
\hline Obat emergency & 1 & $6.250,00$ & $6.250,00$ \\
\hline \multicolumn{3}{|c|}{ Harga untuk satu kali tindakan hemodialisa } & $50.285,00$ \\
\hline \multicolumn{4}{|c|}{ Obat rutin/minggu } \\
\hline Asam folat & 21 & 138,00 & $2.898,00$ \\
\hline Natrium bikarbonat & 21 & 125,00 & $2.625,00$ \\
\hline $\mathrm{CaCO}_{3}$ & 21 & 537,00 & $11.277,00$ \\
\hline Epotrex & 1 & $111.250,00$ & $111.250,00$ \\
\hline \multicolumn{3}{|c|}{ Harga untuk satu kali tindakan hemodialisa } & $64.025,00$ \\
\hline \multicolumn{4}{|c|}{ Obat rutin/tahun } \\
\hline Rinofer & 2 & $93.500,00$ & $187.000,00$ \\
\hline \multicolumn{3}{|c|}{ Harga untuk satu kali tindakan hemodialisa } & $1.948,00$ \\
\hline \multicolumn{3}{|c|}{ Total harga obat untuk satu kali tindakan hemodialisa } & $116.257,00$ \\
\hline
\end{tabular}


Berdasarkan data pada Tabel 7, biaya obat yang digunakan setiap HD yaitu $\mathrm{NaCl}$, inviclot, dan obat emergensi sebesar Rp44.035,00. Penggunaan epotrex setiap minggu sekali, untuk setiap pasien sedangkan penggunaan rinofer berdasarkan hasil pemeriksaan laboratorium. Kedua obat tersebut diberikan kepada pasien tanpa dikenakan biaya tambahan. Biaya HD yang menggunakan epotrex sebesar = $((\mathrm{Rp} 4.222 .455,00)+(4 \times \mathrm{Rp} 111.250,00))=$ Rp4.667.455,00/bulan.
Jika menggunakan rinofer = $((\mathrm{Rp} 4.222 .455,00)+(1 \times R p 93.500,00))=$ Rp4.315.955,00/bulan.

Biaya HD menggunakan epotrex dan rinofer sebesar $=\mathrm{Rp} 4.667 .455,00+$ Rp93.500,00 = Rp4.760.955,00.

Dengan demikian biaya rata-rata $\mathrm{HD}$ per bulan $=((8 \mathrm{xRp} 418.125,00)+(1 \mathrm{x}$ Rp223.500,00) $+(8 x R p 26.240,00)+(8 x$ $\mathrm{Rp} 44.035,00)+(8 \times R p 50.000,00))=$ Rp4.222.455,00.

Tabel 8. Perbandingan biaya hemodialisa di Rumah Sakit X

\begin{tabular}{lcrr}
\hline \multirow{2}{*}{ Jenis Biaya } & \multicolumn{3}{c}{ Rata-rata Biaya Hemodialisa (n=74) } \\
\cline { 2 - 4 } & Per Tahun (Rp) & Per Bulan (Rp) & Per Kunjungan (Rp) \\
\hline INA CBGs & $68.548 .154,00$ & $5.765 .629,00$ & $879.100,00$ \\
Riil & $54.729 .478,00$ & $4.602 .046,00$ & $705.523,00$ \\
Ideal & $81.221 .976,00$ & $6.826 .476,00$ & $1.056 .946,00$ \\
\hline
\end{tabular}

Evaluasi Biaya

Berdasarkan data pada Tabel 8, tarif untuk satu kali HD atau per kunjungan yang diberikan oleh RS $\mathrm{X}$ untuk unit hemodialisa pasien asuransi adalah sebesar Rp1.100.000,00 sedangkan biaya riil lebih rendah yaitu sebesar Rp705,523,00, sedangkan tarif yang diberikan oleh pemerintah (INA CBGs) lebih tinggi yaitu sebesar
Rp879.100,00, adapun biaya ideal lebih tinggi yaitu sebesar Rp1.056.946,00. Biaya ideal di dalam penelitian ini adalah jumlah rata-rata biaya yang dikeluarkan oleh RS untuk pengobatan pasien PGK HD, hanya pada terapi anemia (penggunaan epotrex dan rinofer serta transfusi). Perhitungan rata-rata biaya pertahun dan perbulan dapat dilihat pada Persamaan 1 dan 2.

Perhitung an rata - rata biaya per tahun $=\frac{\text { [umlah biaya medis langsung } 74 \text { pasien selama satu tahun }}{\text { 「umlah frekuensi HD } 74 \text { pasien se } \text { ama satu tahun }}$

Perhitungan rata - rata biaya per bulan $=\frac{\text { Rata }- \text { rata biaya per tahun }}{12 \text { bulan }}$ 
Berdasarkan data pada Tabel 8, dapat dikatakan bahwa rumah sakit mengalami keuntungan karena biaya riil ternyata lebih rendah daripada tarif yang ditetapkan RS dan tarif yang ditetapkan pemerintah (INA CBGs). Namun dengan keuntungan sejumlah itu belum dapat dikatakan RS untung karena ada fixed cost yang harus dihitung. Sedangkan berdasarkan biaya ideal lebih tinggi dari semua biaya tersebut. Tarif dapat berada di bawah, sama, atau di atas unit cost. Dari hasil statistik mengenai perbandingan antara biaya riil dan biaya ideal, menyatakan perbedaan bermakna dengan nilai $p<0,05(p=0,018)$.

\section{Simpulan}

Rata-rata biaya riil untuk satu kali hemodialisa sejumlah Rp705.523,00, biaya ideal berdasarkan terapi manajemen anemia sejumlah Rp1.056.946, tarif INA CBGs sejumlah Rp879.100,00. Komponen biaya hemodialisa meliputi biaya hemodialisa set, pemeriksaan laboratorium, obat, bahan habis pakai atau alat kesehatan, dan konsultasi dokter. Biaya yang terbesar adalah hemodialisa set sejumlah Rp548.750,00 dan biaya konsultasi dokter sejumlah Rp50.000,00.

\section{Ucapan Terima Kasih}

Penulis berterima kasih kepada Direktur Rumah Sakit $\mathrm{X}$ atas kolaborasi selama proses pengumpulan data. Kami berharap bahwa hasil penelitian ini dapat bermanfaat bagi kemajuan ilmu pengetahuan dan meningkatkan derajat kesehatan masyarakat, terutama bagi pasien dengan penyakit ginjal kronik yang menjalani hemodialisa.

\section{Daftar Pustaka}

Azalea, M. Andayani, T.M., Satibi. 2016. Analisis biaya pengobatan penyakit ginjal kronis rawat inap dengan hemodialisis di rumah sakit. Jurnal Manajemen dan Pelayanan Farmasi, 6(2):141150.

Firda, T. dan Thabrany, H. 2016. Biaya dan outcome hemodialisis di rumah sakit kelas B dan C. Jurnal Ekonomi Kesehatan Indonesia, 1(1):54-64.

Kementerian Kesehatan Republik Indonesia. 2017. Info Datin Pusat Data dan Informasi Kementerian Kesehatan RI. Jakarta: Kementerian Kesehatan Republik Indonesia.

Supadmi, W. 2011. Evaluasi penggunaan obat antihipertensi pada pasien gagal ginjal kronik yang menjalani hemodialisa. Jurnal Ilmiah Kefarmasian, 19(1):6780.

Wiguna, G.N.C., Ahmad, R.A., Utarini, A. 2013. Biaya pelayanan hemodialisis peserta asuransi kesehatan menurut perspektif pasien di RSUD tipe B Provinsi Bali. Jurnal Manajemen Pelayanan Kesehatan, Volume 16(1):37-45.

Fitria, D.Y. 2015. Analisa drug related problems (DRPS) pada pasien rawat inap penyakit ginjal kronik dengan penyakit penyerta di Rumkital Dr. Mintohardjo tahun 2014. Skripsi. Program Studi 
PHARMACY: Jurnal Farmasi Indonesia

p-ISSN 1693-3591

(Pharmaceutical Journal of Indonesia)

e-ISSN 2579-910X

Vol.16 No. 02 Desember 2019:386-395

Farmasi, Fakultas Kedokteran

Islam Negeri Syarif Hidayatullah dan IImu Kesehatan, Universitas Jakarta. 